This item was submitted to Loughborough's Research Repository by the author.

Items in Figshare are protected by copyright, with all rights reserved, unless otherwise indicated.

\title{
The impact of substrate temperature on the size and aspect ratio of inkjet- dissolved via holes in thin poly(4-vinyl phenol) dielectric layers
}

\section{PLEASE CITE THE PUBLISHED VERSION}

http://dx.doi.org/10.1063/1.4795447

\section{PUBLISHER}

(c) American Institute of Physics

\section{VERSION}

VoR (Version of Record)

\section{LICENCE}

CC BY-NC-ND 4.0

\section{REPOSITORY RECORD}

Zhang, Yan, Changqing Liu, and David C. Whalley. 2019. "The Impact of Substrate Temperature on the Size and Aspect Ratio of Inkjet-dissolved via Holes in Thin Poly(4-vinyl Phenol) Dielectric Layers". figshare. https://hdl.handle.net/2134/11969. 


\section{AIP Applied Physics \\ Letters}

\section{The impact of substrate temperature on the size and aspect ratio of inkjet- dissolved via holes in thin poly(4-vinyl phenol) dielectric layers}

Y. Zhang, C. Liu, and D. C. Whalley

Citation: Appl. Phys. Lett. 102, 103303 (2013); doi: 10.1063/1.4795447

View online: http://dx.doi.org/10.1063/1.4795447

View Table of Contents: http://apl.aip.org/resource/1/APPLAB/v102/i10

Published by the American Institute of Physics.

\section{Related Articles}

The impact of substrate temperature on the size and aspect ratio of inkjet-dissolved via holes in thin poly(4-vinyl phenol) dielectric layers

APL: Org. Electron. Photonics 6, 46 (2013)

Rapid formation of $\mathrm{Cu} / \mathrm{Cu} 3 \mathrm{Sn} / \mathrm{Cu}$ joints using ultrasonic bonding process at ambient temperature Appl. Phys. Lett. 102, 094104 (2013)

Three-dimensional imaging of copper pillars using x-ray tomography within a scanning electron microscope: A simulation study based on synchrotron data

Rev. Sci. Instrum. 84, 023708 (2013)

Comparison of thermomigration behaviors between $\mathrm{Pb}$-free flip chip solder joints and microbumps in three dimensional integrated circuits: Bump height effect

J. Appl. Phys. 113, 043711 (2013)

Evidence of ultra-low-k dielectric material degradation and nanostructure alteration of the Cu/ultra-low-k interconnects in time-dependent dielectric breakdown failure

Appl. Phys. Lett. 102, 022908 (2013)

\section{Additional information on Appl. Phys. Lett.}

Journal Homepage: http://apl.aip.org/

Journal Information: http://apl.aip.org/about/about_the_journal

Top downloads: http://apl.aip.org/features/most_downloaded

Information for Authors: http://apl.aip.org/authors

\section{ADVERTISEMENT}

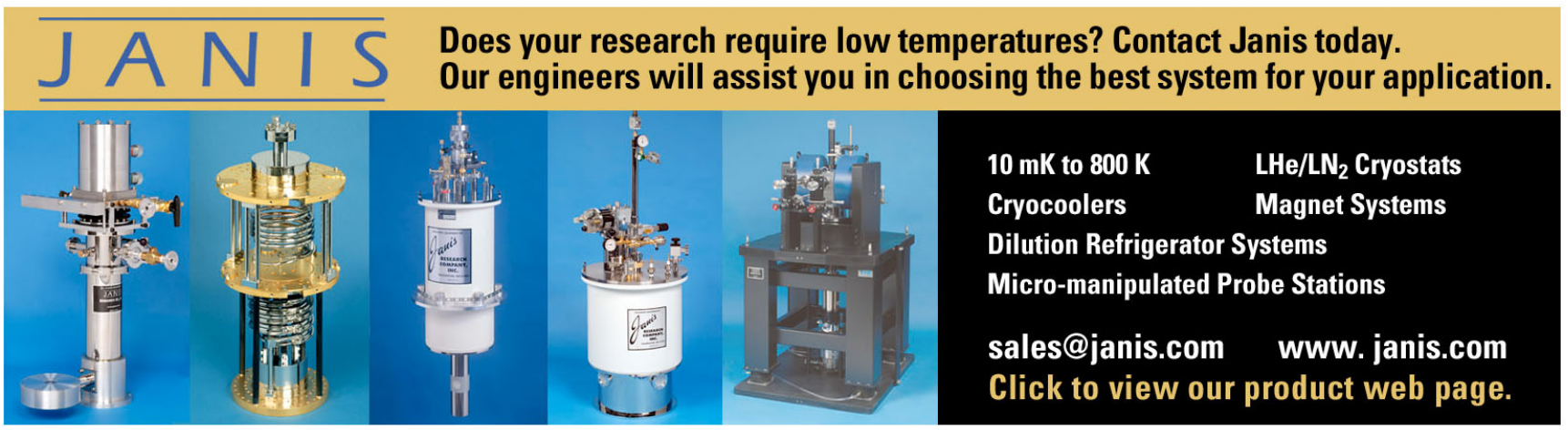




\title{
The impact of substrate temperature on the size and aspect ratio of inkjet-dissolved via holes in thin poly(4-vinyl phenol) dielectric layers
}

\author{
Y. Zhang (张岩), C. Liu, ${ }^{\text {a) }}$ and D. C. Whalley \\ Wolfson School of Mechanical and Manufacturing Engineering, Loughborough University, Loughborough, \\ Leicestershire, LE11 3TU, United Kingdom
}

(Received 1 October 2012; accepted 1 March 2013; published online 14 March 2013)

\begin{abstract}
The authors demonstrate the effect of substrate temperature on the relationship between the inkjet-etched via hole size and the number of drops of etchant dispensed. A mechanism for the different via hole size evolution versus the number of drops is proposed. An explanation for the interrelationship between the solvent evaporation rate and polymer re-deposition is presented. The aspect ratio of via holes produced is found to increase with the substrate temperature. Therefore, higher temperatures can be used to reduce the size and increase the aspect ratio of via holes fabricated by inkjet etching. (C) 2013 American Institute of Physics.

[http://dx.doi.org/10.1063/1.4795447]
\end{abstract}

Inkjet, as a digitally driven and non-contact printing method, has been used for various electronics manufacturing applications, such as transistor and organic light-emitting diode (OLED) fabrication, ${ }^{1-5}$ polymer structural patterning, ${ }^{6-12}$ microlenses, ${ }^{13-15}$ and other fields over the last decade as printed electronics has attracted great interest both in academia and in industrial application. One recently emerged investigation is the use of inkjet printing as a subtractive etching process rather than an additive manufacturing technique, which is what inkjet printing is usually utilized for. This is of particular interest because it has the potential to enable production of all-inkjet-printed circuits and to facilitate process integration, as it offers an alternative data-driven via hole fabrication solution for vertical electrical interconnection between multiple layers other than mechanical drilling and laser ablation. Kawase et al. ${ }^{16}$ demonstrated dissolving via holes by inkjet printing of ethanol drops onto poly(4-vinyl phenol) (PVPh) layers. They reported the independence of via hole outer diameter as produced by inkjet printing from the number of drops dispensed. de Gans et al., ${ }^{10}$ however, obtained a power law relationship between outer diameter and the number of drops used. Xia et al. ${ }^{17,18}$ reported the existence of a thin residual polymer layer in the center of the hole and the removal of this polymer residue by repeatedly dispensing solvent drops at the same location. It is under such circumstance that the development of diameter with the number of solvent drops is important. Therefore, a more comprehensive investigation was initiated, based on their work, and including a systematic study of the relationship between the diameter of inkjet-dissolved via holes, and the number of drops dispensed and the droplet ejection frequency, which was presented by Zhang et al. ${ }^{19}$ Nonetheless, the aforementioned experiments were carried out at room temperature and little is known about the relationship between the via hole size and drop numbers at higher temperatures, which is important as solvent evaporation strongly depends on temperature and is a key factor in the inkjet etching process. Therefore, adjusting the temperature of the printing stage is anticipated to allow modulation of the

\footnotetext{
${ }^{\text {a) }}$ Author to whom correspondence should be addressed. Electronic mail: C.Liu@lboro.ac.uk.
}

size of the via holes produced. In this paper, we experimentally demonstrate the evolution of via hole dimensions versus the number of drops at elevated temperatures, providing a potential means to decrease the hole diameter and increase the aspect ratio of inkjet-etched via holes.

$\mathrm{PVPh}$ solution was made by dissolving the polymer $\left(M_{w}=11000\right.$, monomer $\leq 0.2 \mathrm{wt}$. \%) into isopropyl alcohol (IPA) and breaking up agglomeration using an ultrasonic bath. The concentration of the polymer solution was about $20 \mathrm{wt} . \%$. The PVPh solution was spin coated onto glass substrates that had been previously washed with Decon 90 and then acetone to deposit a thin PVPh film, which was subsequently dried in air for $24 \mathrm{~h}$. The spin coating speed and time were set to $2000 \mathrm{rpm}$ and $40 \mathrm{~s}$, respectively, and the resulting PVPh thickness was measured to be approximately $2.5 \mu \mathrm{m}$ using a chromatic light aberration (CLA) microscope. A Microfab Jetlab ${ }^{\circledR}$ 4 printer with a $60 \mu \mathrm{m}$ nozzle was employed in this work to dispense ethanol (200 proof) drops as the etchant. When finding the jetting parameters for ethanol, the waveform should be such that no satellite drops can be observed behind the main ethanol drop and the trajectory of the main drop should be highly repeatable with minimum deviation. This is to ensure that multiple drops land at the same location to penetrate and dissolve the PVPh layer, thereby forming the via hole. The stand-off distance between the inkjet nozzle and the substrate was also minimized by bringing the print head as close to the printing stage as possible to minimize trajectory deviation caused by the drag effect from air currents ${ }^{20}$ so that any remaining droplet trajectory deviation would not significantly affect its substrate landing position. This distance between the nozzle tip and the top surface of the glass substrate was approximately $3.5 \mathrm{~mm}$. A unipolar waveform with jetting parameters set to $U_{d w e l l}=55 \mathrm{~V}$ and $t_{d w e l l}=45 \mu \mathrm{s}$ was applied to the piezoelectric-material-operated print head to generate ethanol drops. The diameter of the corresponding droplet induced was estimated to be $56 \mu \mathrm{m}$ using the drop analysis function incorporated within the printer. The droplet ejection frequency used was $1 \mathrm{~Hz}$, resulting in a $1 \mathrm{~s}$ interval between two consecutive drops. Profiles of the via holes produced were obtained using a white light interferometry (WLI) microscope. Figures 1(a) and 1(b) illustrate the evolution of the via 

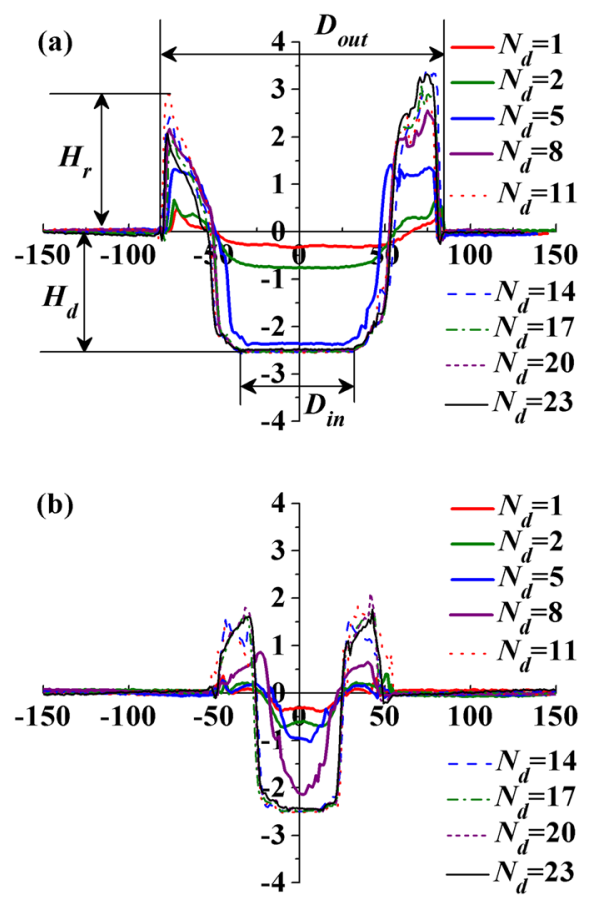

FIG. 1. (a) Superimposition of the via hole profile evolution versus the number of drops $\left(N_{d}\right)$ in a thin $\mathrm{PVPh}$ polymer film at $20^{\circ} \mathrm{C}$ and an indication of where outer diameter $\left(D_{\text {out }}\right)$, inner diameter $\left(D_{\text {in }}\right)$, ridge height $\left(H_{r}\right)$, and the depth of via hole $\left(H_{d}\right)$ are taken for a via hole created by 11 ethanol drops. (b) Superimposition of the via hole profile evolution versus the number of drops $\left(N_{d}\right)$ in a thin $\mathrm{PVPh}$ polymer film at $80^{\circ} \mathrm{C}$.

hole profile versus the number of drops $\left(N_{d}\right)$ at $20^{\circ} \mathrm{C}$ and $80^{\circ} \mathrm{C}$, respectively. The outer diameter $\left(D_{\text {out }}\right)$, inner diameter $\left(D_{i n}\right)$, ridge height $\left(H_{r}\right)$, and the depth of the hole $\left(H_{d}\right)$, as defined in Figure 1(a) for a via hole produced by 11 drops, were measured using the WLI microscope. It should be noted that the vertical axes in Figure 1 have been rescaled to show the ridge height.
Figure 2 illustrates the development of $D_{\text {out }}, D_{i n}, H_{d}$, and $H_{r}$ versus $N_{d}$ at different substrate temperatures. It can be seen from Figure 2(a) that $D_{\text {out }}$ for all stage temperatures is independent of $N_{d}$ and remains constant during the etching process. The drop evaporates faster at higher temperatures, even before it touches the substrate surface, and the contact time between the drop and the substrate is shorter. Therefore, the drop is smaller when it is deposited, and $D_{\text {out }}$ is, thus, also smaller.

As shown in Figure 2(b), at $20^{\circ} \mathrm{C} D_{\text {in }}$ decreases first with increasing $N_{d}$ and then levels off to a constant, which is in agreement with our previous result without substrate heating. ${ }^{19}$ However, the evolution of $D_{\text {in }}$ versus $N_{d}$ becomes different at higher temperatures. $D_{i n}$ first decreases with $N_{d}$ and then increases before it eventually levels off to a constant, resembling a spoon-like cross section, as shown in Figure 2(b) at $40^{\circ} \mathrm{C}-80^{\circ} \mathrm{C}$. This is postulated to be caused by the relationship between solvent evaporation and polymer re-deposition within the sessile drop caused by the coffee ring or coffee stain effect. The coffee ring effect is a phenomenon in which dispersed particles or dissolved materials in a solvent are transferred to the drop border due to a pinned contact line and faster evaporation there, which causes outward microfluidic flows as a result of solvent replenishment from the center to the border of the contact area. ${ }^{21-23}$ When an elevated temperature is applied to the printing stage, there is a fast dissolution of the uppermost polymer layer and thus the coffee stain effect is pronounced for the first drop. A simplified approximation for sessile drop evaporation ${ }^{24}$ is utilized to estimate the time scale and it is calculated to be $0.6 \mathrm{~s}$ for the evaporation of the sessile drop from the PVPh surface at $20^{\circ} \mathrm{C}$. Therefore, it is believed that the sessile drop evaporates substantially before the next drop merges in. With increasing number of drops, the polymer is increasingly softened and dissolved. However, since the evaporation is fast after each drop deposition at higher temperatures, even though more polymer is dissolved, it cannot be transported to the rim completely. Hence $D_{\text {in }}$
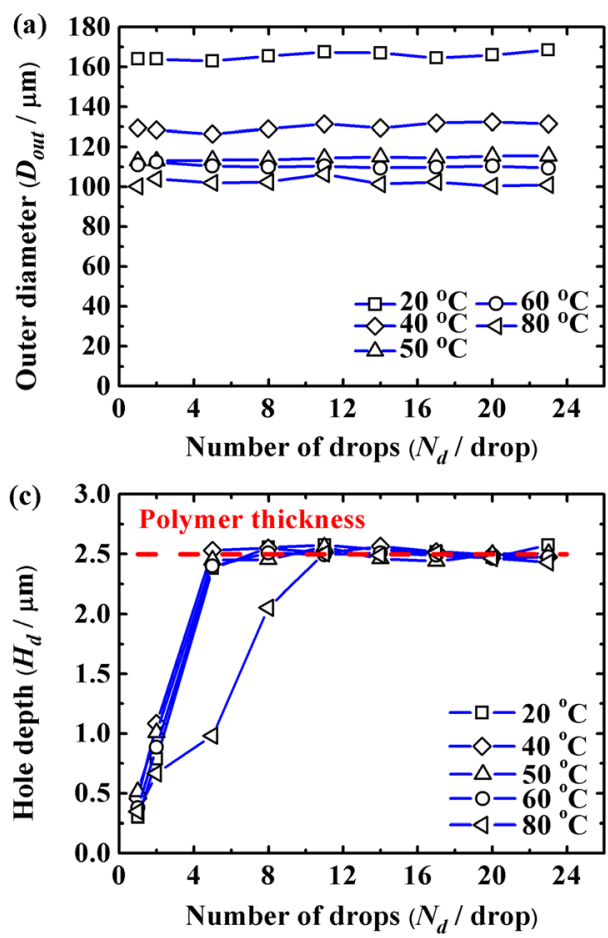
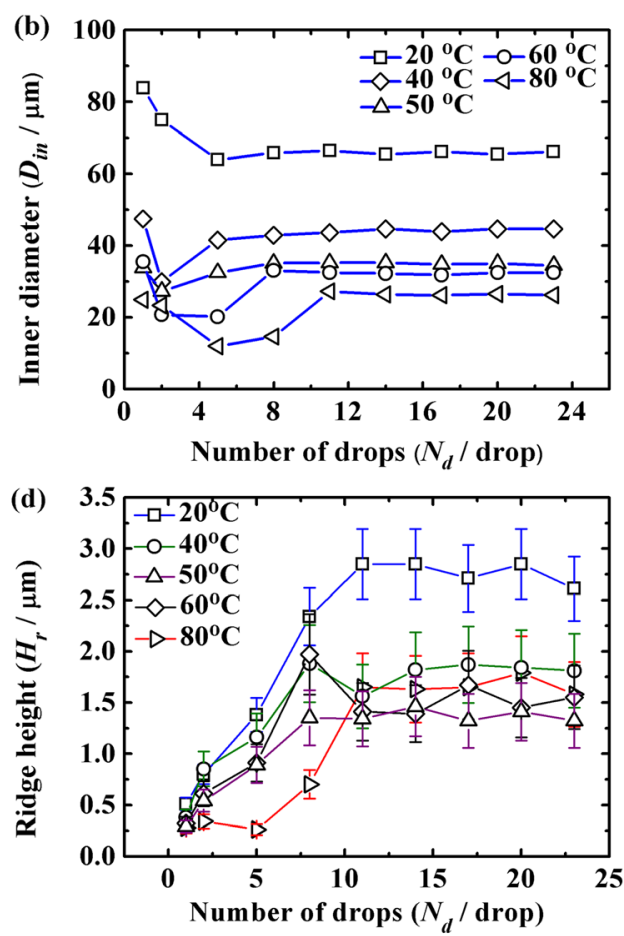

FIG. 2. (a) The evolution of $D_{\text {out }}$ versus $N_{d}$ at different printing stage temperatures at a droplet ejection frequency of $1 \mathrm{~Hz}$. (b) The evolution of $D_{\text {in }}$ versus $N_{d}$ at different printing stage temperatures. (c) The profile of $H_{d}$ versus $N_{d}$ at different printing stage temperatures. The dashed line indicates the polymer thickness. (d) The evolution of $H_{r}$ versus $N_{d}$ at different temperatures. 

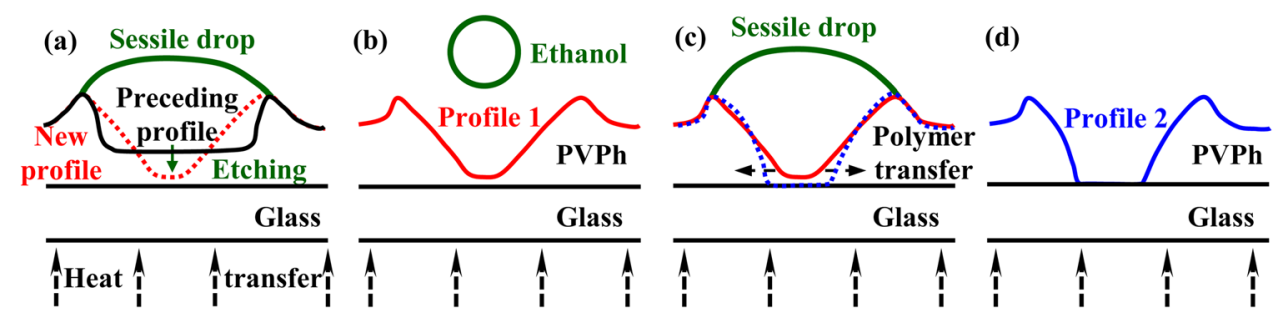

FIG. 3. A schematic illustration of the proposed mechanism of via hole profile evolution with $N_{d}$ for ethanol drops at higher temperatures. (a) A sessile drop wets the patterned polymer layer (up to its ridge at maximum distance) dissolving more polymer further down the PVPh film and the dissolved polymer gets re-deposited at the periphery, as indicated by the dotted line. (b) A new via hole forms after solvent evaporation. (c) Another drop wets within the hole (up to its ridge at maximum distance) and keeps transferring the dissolved polymer outward leading to a larger $D_{\text {in }}$ due to a faster flow velocity closer to the contact line. (d) The new profile after the PVPh film is thoroughly penetrated, and the solvent completely evaporates when the maximum transfer distance is achieved.

decreases first with $N_{d}$ resulting in the profile changing from the solid line to the dotted line, as illustrated in Figure 3(a). When most of the polymer is removed from the center with a further increasing of $N_{d}$, the polymer from the sidewalls starts being transported to the rim. Due to a faster transport velocity closer to the contact line, ${ }^{16} D_{\text {in }}$ increases further even though the ethanol sessile drop evaporates drastically at higher temperatures. Therefore, the via hole profile evolves from the solid line to the dotted line, as sketched in Figure 3(c). The sidewalls become steeper as shown in Figure 1(b). When the maximum distance is achieved, the final profile remains independent of $N_{d}$, as shown in Figure 3(d). The higher the temperature, the faster the evaporation compared to the dissolution. Thus, more drops are needed for the same resulting structure. This is clearly demonstrated in Figure 2(b) where the higher the temperature, the larger the "bowl" of the "spoon", and the shorter the "handle". This can also be observed more clearly from the hole profile superimposition in Figure 1. It almost reaches the bottom of the hole with 5 ethanol drops at $20^{\circ} \mathrm{C}$, as shown in Figure $1($ a), while only etches less than half way down the PVPh layer at $80^{\circ} \mathrm{C}$, as shown in Figure 1(b). $H_{r}$ does not change much once the PVPh layer is completely etched through, as illustrated in Figure 2(d), and it is much higher at $20^{\circ} \mathrm{C}$ than at higher temperatures. It is speculated that the ridge height is likely to scale with the volume of the via hole generated since it is formed by redeposition of the dissolved polymer from within the hole.

As illustrated in Figure 2(c), the etching rate is not greatly compromised for high temperatures below the boiling point of the solvent, which for ethanol is $78^{\circ} \mathrm{C}$. The polymer layer is considered to be thoroughly penetrated after 5 drops for temperatures below the boiling point, i.e., $H_{d}$ approaches the polymer thickness. Above the boiling point, more than 8 drops are needed to completely penetrate the PVPh layer due to the extremely fast solvent evaporation. The aspect ratios of completely etched via holes, which are produced by no less than 11 drops, as calculated by both $H_{d} / D_{\text {out }}$ and $H_{d} / D_{\text {in }}$ are given in Figure 4(a). It can be clearly seen that the aspect ratio of the via holes increases with temperature, since both $D_{\text {out }}$ and $D_{\text {in }}$ decrease with increasing temperature for completely etched via holes, and the aspect ratio increases more strongly for $H_{d} / D_{i n}$ than for $H_{d} /$ $D_{\text {out }}$. This can be used as a method to reduce the size and increase the aspect ratio of via holes produced using the inkjet etching technique. The $D_{\text {out }} / D_{\text {in }}$ ratios for completely etched via holes after 11 drops at different temperatures are supposed to give an indication of the change of structure parameters with temperature. As sketched in Figure 4(b), $D_{\text {out }} / D_{\text {in }}$ increases with temperature, which indicates that sidewalls become even less steep at higher temperatures. This, however, is in contradiction with the sketch of sidewall slope with temperature in Figure 4(c), which markedly shows an increasing sidewall slope with temperature. This
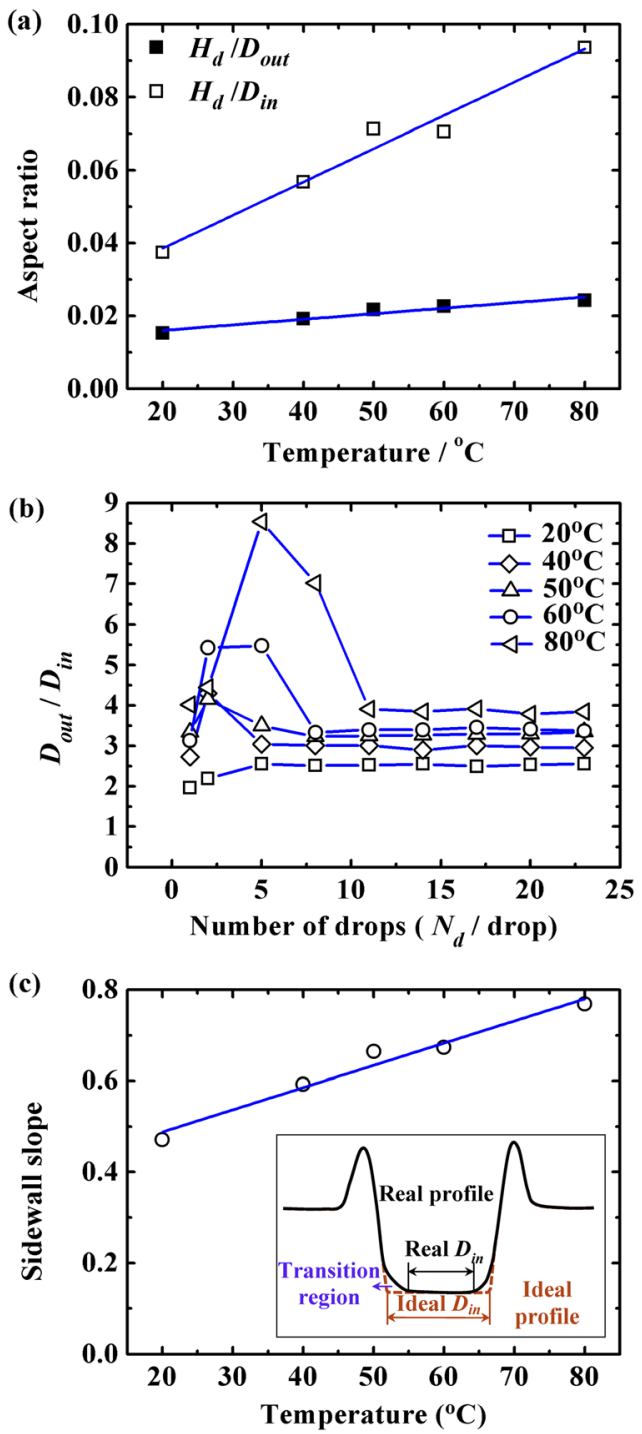

FIG. 4. (a) The aspect ratio of inkjet-etched via holes versus temperature. Dimensions $\left(H_{d}\right.$ and $\left.D_{i n}\right)$ are taken from completed etched via holes. (b) $D_{\text {out }} / D_{\text {in }}$ versus $N_{d}$ at different temperatures. (c) Sidewall slope of the completely etched via holes versus temperature with an inset illustration of the difference between an ideal and practical via hole profile. 
contradiction is believed to be caused by the difference between the ideal and actual $D_{i n}$, as illustrated in the Figure 4(c) inset. Rather than an ideal sharp border between the sidewall and the bottom, a blunt transition area can be observed from the via hole profiles. This is caused by the inward polymer diffusion back to the center in the presence of a polymer concentration gradient within the solvent drop. The actual $D_{i n}$ obtained is smaller than the ideal size.

Inkjet etching of via holes is a research area of great interest as it paves the way for all-inkjet-printed electronics integration, eliminating the alignment issue that can arise when several separate processes are used for the fabrication of various structures. This paper presented the results of the investigation into the effect of substrate temperature on the structural parameters of the via holes produced by inkjet etching. Applying higher temperatures provides a method to decrease via hole diameters and increase their aspect ratio without switching to a smaller nozzle. The ridge height of the via holes does not change significantly once the polymer layer is completely etched through. The sidewall of the completely etched via holes becomes steeper with increasing temperature. The evolution of via hole inner diameter with the number of drops at higher temperatures was found to feature a spoon-shaped cross section. The relationship between the outward polymer transfer induced by the coffee ring effect with a faster velocity closer to the contact line and the accelerated solvent evaporation caused by high temperatures was proposed as a mechanism to explain the curve.

${ }^{1}$ G. L. Whiting and A. C. Arias, Appl. Phys. Lett. 95, 253302 (2009).

${ }^{2}$ T. Kawase, T. Shimoda, C. Newsome, H. Sirringhaus, and R. H. Friend, Thin Solid Films 438-439, 279 (2003).
${ }^{3}$ S. Gamerith, A. Klug, H. Scheiber, U. Scherf, E. Moderegger, and E. List, Adv. Funct. Mater. 17, 3111 (2007).

${ }^{4}$ Y. Nobusa, Y. Yomogida, S. Matsuzaki, K. Yanagi, H. Kataura, and T. Takenobu, Appl. Phys. Lett. 99, 183106 (2011).

${ }^{5}$ H. Sirringhaus, T. Kawase, R. H. Friend, T. Shimoda, M. Inbasekaran, W. Wu, and E. P. Woo, Science 290, 2123 (2000).

${ }^{6}$ B. J. de Gans and U. S. Schubert, Langmuir 20, 7789 (2004).

${ }^{7}$ B. J. de Gans, S. Hoeppener, and U. S. Schubert, Adv. Mater. 18, 910 (2006).

${ }^{8}$ S. Karabasheva, S. Baluschev, and K. Graf, Appl. Phys. Lett. 89, 031110 (2006).

${ }^{9}$ R. Pericet-Camara, E. Bonaccurso, and K. Graf, ChemPhysChem 9, 1738 (2008).

${ }^{10}$ B. J. de Gans, S. Hoeppener, and U. S. Schubert, J. Mater. Chem. 17, 3045 (2007).

${ }^{11}$ I. A. Grimaldi, A. De Girolamo Del Mauro, G. Nenna, F. Loffredo, C. Minarini, and F. Villani, J. Appl. Polym. Sci. 122, 3637 (2011).

${ }^{12}$ G. F. Li, K. Graf, E. Bonaccurso, D. S. Golovko, A. Best, and H. J. Butt, Macromol. Chem. Phys. 208, 2134 (2007).

${ }^{13}$ E. Bonaccurso, H. J. Butt, B. Hankeln, B. Niesenhaus, and K. Graf, Appl. Phys. Lett. 86, 124101 (2005).

${ }^{14}$ R. Pericet-Camara, A. Best, S. K. Nett, J. S. Gutmann, and E. Bonaccurso, Opt. Express 15, 9877 (2007).

${ }^{15}$ I. A. Grimaldi, A. De Girolamo Del Mauro, F. Loffredo, G. Nenna, F. Villani, and C. Minarini, Proc. SPIE 8082, 808244 (2011).

${ }^{16}$ T. Kawase, H. Sirringhaus, R. H. Friend, and T. Shimoda, Adv. Mater. 13, 1601 (2001).

${ }^{17}$ Y. J. Xia and R. H. Friend, Appl. Phys. Lett. 88, 163508 (2006).

${ }^{18}$ Y. J. Xia and R. H. Friend, Appl. Phys. Lett. 90, 253513 (2007).

${ }^{19}$ Y. Zhang, C. Liu, and D. C. Whalley, J. Phys. D: Appl. Phys. 45, 125303 (2012).

${ }^{20}$ B. Derby, Annu. Rev. Mater. Res. 40, 395 (2010).

${ }^{21}$ R. D. Deegan, Phys. Rev. E 61, 475 (2000).

${ }^{22}$ R. D. Deegan, O. Bakajin, T. F. Dupont, G. Huber, S. R. Nagel, and T. A. Witten, Nature 389, 827 (1997).

${ }^{23}$ R. D. Deegan, O. Bakajin, T. F. Dupont, G. Huber, S. R. Nagel, and T. A. Witten, Phys. Rev. E 62, 756 (2000).

${ }^{24}$ F. Schönfeld, K. H. Graf, S. Hardt, and H. J. Butt, Int. J. Heat Mass Transfer 51, 3696 (2008). 